\title{
A pilot study to determine if intraocular lens choice at the time of cataract surgery has an impact on patient-reported driving habits
}

This article was published in the following Dove Press journal:

Clinical Ophthalmology

28 August 2015

Number of times this article has been viewed

\author{
George HH Beiko',2 \\ 'Department of Ophthalmology and \\ Vision Sciences, University of Toronto, \\ Toronto, ON, Canada; ${ }^{2}$ Division \\ of Ophthalmology, Department of \\ Surgery, McMaster University, \\ Hamilton, ON, Canada
}

Purpose: To determine if intraocular lens (IOL) choice at the time of cataract surgery affects driving habits.

Materials and methods: Pseudophakes who were 28-35 months postbilateral cataract surgery with one of two contemporary one-piece hydrophobic acrylic IOLs (SN60WF or ZCB00) were asked to complete the Driving Habits Questionnaire, a validated instrument for determining self-reported driving status, frequency, and difficulty. To determine if there were any differences in driving habits between the two groups, $t$-tests and $\chi^{2}$ tests were used.

Results: Of 90 respondents, 72 (40 SN60WF and 32 ZCB00) were still active drivers. The SN60WF-implanted subjects were less likely to drive at the same speed or faster than the general flow of traffic, less likely to rate their quality of driving as average/above average, less likely to have traveled beyond their immediate neighborhood, less likely to drive at night, more likely to have moderate-to-severe difficulty driving at night, and more likely to have self-reported road traffic accidents. The differences did not reach statistical significance.

Conclusion: Changes in patients' driving habits 2-3 years after cataract surgery may be associated with the type of IOL implanted. A larger study, powered to demonstrate statistical significance, is needed to verify the trends identified in this pilot study and discover possible contributing factors.

Keywords: intraocular lens, cataract surgery, driving habits, disability glare, retinal straylight, accidents

\section{Introduction}

Cataract is the leading cause of visual impairment in the USA. There are 20.5 million people with cataracts in the USA, and that number is expected to rise to 30.1 million by 2030 . Cataracts reduce visual acuity and contrast sensitivity, and increase disability glare from intraocular retinal straylight. ${ }^{1}$

Visual deficits from cataract can affect driving performance and increase vehiclecrash risk. ${ }^{2,3}$ Disability glare may affect older drivers early in the development of cataract, even while visual acuity is still within legal limits for driving. Van Den Berg et al found that nearly one-third of drivers aged 75 years and older have disability glare, which was defined as at least a fourfold increase in retinal straylight above normal levels. ${ }^{4}$

In certain circumstances, such as night driving with oncoming headlights, the light scattering from disability glare can have a greater impact on visual performance than decreased visual acuity does. ${ }^{5}$ This may be one reason that disability glare has been reported to be a significant cause of nighttime motor vehicle accidents.

Visual impairment from cataract and other age-related eye diseases has been linked to changes in driving habits, including driving cessation. ${ }^{6-9}$ Common self-regulating
Correspondence: George HH Beiko I 80 Vine Street - Suite 103, St

Catharines, ONT L2R 7P3, Canada

$\mathrm{Tel}+\mathrm{I} 9056878322$

Fax +l 9056878766

Email georgebeiko@hotmail.com 
behaviors include avoiding driving at night, on the highway, in the rain, or in unfamiliar locations.

Deficits other than acuity may factor prominently in driving habits. Older patients who avoid night driving, for example, have significantly higher straylight values than those who continue to drive at night. ${ }^{10}$ Impaired contrast sensitivity has been associated with increased motor vehicle-collision risk, self-regulation of driving habits, and driving cessation., ${ }^{2,11}$

While adjusting their driving habits may help older adults avoid crashes, reduced driving ability is also significantly associated with increased depressive symptoms ${ }^{9}$ and reduced mobility and independence.

\section{Impact of cataract surgery on vision and driving}

Cataract surgery with intraocular lens (IOL) implantation has an immediate effect on visual performance, returning visual acuity, contrast sensitivity, and disability glare to within normal limits. ${ }^{3}$ Patients who have undergone cataract/IOL surgery have half the rate of crash involvement of cataract patients who have not undergone surgery. ${ }^{12}$ Within a few months, postcataract/IOL surgery, there is a dramatic decrease in the percentage of patients who report difficulty with daytime driving (from $50 \%$ to $6 \%$ ) and nighttime driving (from $79 \%$ to $34 \%$ ). ${ }^{13}$

Improvement in self-reported driving ability after cataract surgery seems to be more closely associated with improved contrast sensitivity in the operated eye than with visual acuity. ${ }^{14}$

Although confidence and performance in driving is increased in the early postoperative period, difficulty with nighttime driving has been reported to increase over time, with $43 \%$ of those 5 years postcataract/IOL surgery reporting difficulty. ${ }^{13}$

The purpose of this study was to determine if the choice of IOL implanted at the time of cataract surgery affects postoperative driving habits, by comparing two widely used hydrophobic acrylic lenses.

\section{Materials and methods}

A retrospective chart review was performed. Subjects from a single center in Canada who had had cataract surgery performed by the author and were implanted bilaterally with one of the two study lenses between November 1, 2009 and April 1, 2011 were reviewed. All were 28-35 months postbilateral cataract surgery. The study lenses were both contemporary hydrophobic acrylic IOLs: the AcrySof ${ }^{\circledR}$ IQ SN60WF monofocal (Alcon Laboratories Inc, Fort Worth,
TX, USA) and the Tecnis $^{\circledR}$ one-piece ZCB00 monofocal (Abbott Medical Optics Inc, Santa Ana, CA, USA).

The SN60WF lens has a single-piece, anterior-asymmetric, biconvex optic with supporting modified-L haptics. The overall length is $13.0 \mathrm{~mm}$, including the $6.0 \mathrm{~mm}$ optic. The lens has a refractive index of 1.55 and a yellow chromophore to filter blue and ultraviolet light.

The ZCB00 lens is a single-piece, biconvex, anterior aspheric optic with a frosted, continuous $360^{\circ}$ posterior square edge and offset $\mathrm{C}$-style haptics. The overall diameter is $13.0 \mathrm{~mm}$, with a $6.0 \mathrm{~mm}$ optic. The optic is clear, with a refractive index of 1.47 .

The inclusion criteria were as follows: participants had to be living independently and legally licensed to drive (regardless of whether they still chose to drive), with best-corrected distance visual acuity of 20/30 or better in each eye, and free of any other eye disease that would limit visual acuity. Determination of ocular health was based on the medical record.

Exclusion criteria for both groups were any macular pathology, glaucoma with any visual field loss, recurrent inflammatory conditions, amblyopia, use of a wheelchair for mobility, and the presence of dementia, Parkinson's disease, psychosis, or any illness that precluded driving a motor vehicle. Patients with any surgical complications, such as capsulorhexis tear or vitreous loss, were also excluded.

The study adhered to the tenets of the Declaration of Helsinki. All persons meeting the inclusion criteria were contacted by a phone call. After the nature and purpose of the study were explained, each subject was asked to provide informed consent before being enrolled in the study.

Participants were asked to take the Driving Habits Questionnaire (DHQ). The DHQ has been previously described in detail, ${ }^{3}$ and has been used extensively to quantify changes in driving patterns. ${ }^{9,11,16}$ It is an investigator-administered instrument that assesses driving habits over the previous year in six different domains: 1) current driving status, 2) driving exposure (days/miles/trips per week), 3) dependence on other drivers, 4) driving difficulty in specific situations and conditions, 5) driving space (distance from home), and 6) self-reported crashes and citations. The DHQ was administered by telephone interview or in person, depending on patient availability, to all subjects. Most comparisons were based on the responses of the active drivers only. Patient demographics were obtained from the patients directly and from the patient record.

\section{Statistical analysis}

Data analysis was performed using Minitab 15 (Minitab Inc, State College, PA, USA). Descriptive statistics were used to 
Table I Subject demographics by intraocular lens (IOL) group

\begin{tabular}{llll}
\hline & SN60WF group & ZCB00 group & P-value \\
\hline Number & 51 & 39 & $76.13 \pm 7.85$ \\
Age (years), mean \pm SD & $77.57 \pm 7.24$ & $13 / 26$ & $0.370^{\#}$ \\
Male/female & $19 / 32$ & $6 / 33$ & $0.700^{*}$ \\
Glaucoma (yes/no) & $6 / 45$ & $6 / 33$ & $0.617^{*}$ \\
Diabetes mellitus (yes/no) & $6 / 45$ & $20.44 \pm 3.45$ & $0.880^{*}$ \\
IOL power, mean \pm SD & $21.08 \pm 3.44$ & $43.26 \pm 6.15$ & $0.217^{\#}$ \\
Months since first surgery, mean \pm SD & $34.59 \pm 1.84$ & $38.36 \pm 6.17$ & \\
Months since second surgery, mean \pm SD & $28.61 \pm 4.36$ & & \\
\hline
\end{tabular}

Notes: \#Analysis of variance; ${ }^{*} \chi^{2}$ test.

Abbreviation: SD, standard deviation.

characterize demographics and prevalence of driving habits in the two IOL groups. To examine differences in driving habits between the two groups, $t$-tests and $\chi^{2}$ tests were used. Significance was defined as $P=0.05$ for all statistical analyses.

\section{Results}

The retrospective chart review was performed in August 2013. It was determined that 135 subjects met the study criteria, and attempts were made to contact each by telephone. Ninety subjects agreed to participate. Of the rest, seven refused participation and 38 could not be contacted during the time that the study was conducted.

Of the 90 participants, 51 were implanted bilaterally with SN60WF lenses and 39 with ZCB00 lenses. The two groups were similar in age, sex, and IOL power (Table 1). Similar numbers of patients in each group had glaucoma and/or diabetes mellitus that was controlled and not associated with any visual loss. The ZCB00-implanted subjects were considerably further out from surgery (38 months vs 28 months for the AcrySof group).

Forty subjects (78.4\%) in the SN60WF group and 32 $(82.1 \%)$ in the ZCB00 group reported that they were still driving. These 72 respondents were considered "active drivers" or "drivers", and were directed to answer the rest of the questionnaire about their driving habits. Current driving habits are reported in Table 2. Compared to the ZCB00implanted subjects, the SN60WF-implanted subjects were less likely to drive at the same speed or faster than the general flow of traffic and less likely to rate their quality of driving as average/above average.

Of those who had stopped driving, all those in the ZCB00 group indicated they were physically unable to drive. In the SN60WF group, a range of reasons were given for driving

Table 2 Current driving

\begin{tabular}{|c|c|c|c|c|}
\hline DHQ item & Response & SN60WF group (\%) & ZCB00 group (\%) & $P$-value* \\
\hline \multirow[t]{2}{*}{ Currently drive? } & Yes & 78.4 & 82.1 & 0.671 \\
\hline & No & 21.6 & 17.9 & \\
\hline \multirow[t]{2}{*}{ Wear glasses or contact lenses when driving? } & Yes & 50.0 & 37.5 & 0.289 \\
\hline & No & 50.0 & 62.5 & \\
\hline \multirow[t]{2}{*}{ Wear seatbelt when driving? } & Yes & 100 & 100 & \\
\hline & No & 0 & 0 & \\
\hline \multirow[t]{2}{*}{ How do you prefer to get around? } & Drive self & 85.0 & 78. 1 & 0.451 \\
\hline & Someone else drive & 15.0 & 21.9 & \\
\hline How fast do you usually drive compared to the general & Same/faster & 80.0 & 93.8 & 0.094 \\
\hline flow of traffic? & Slower & 20.0 & 6.3 & \\
\hline Has anyone suggested over the past year that you limit & Yes & 10.0 & 6.3 & 0.567 \\
\hline or stop driving? & No & 90.0 & 93.8 & \\
\hline \multirow[t]{2}{*}{ How would you rate the quality of your driving? } & Above average & 92.5 & 100 & 0.114 \\
\hline & Average & 7.5 & 0 & \\
\hline If you did not want to drive yourself, how would you get & Ask friend/relative & 77.5 & 78. 1 & 0.823 \\
\hline \multirow[t]{3}{*}{ someplace? } & Taxi/bus & 10 & 6.3 & \\
\hline & Drive self anyway & 10 & 9.4 & \\
\hline & Cancel plans & 2.5 & 6.3 & \\
\hline
\end{tabular}

Note: $* \chi^{2}$ test.

Abbreviation: DHQ, Driving Habits Questionnaire. 
Table 3 Driving Habits Questionnaire: Driving exposure and driving dependency

\begin{tabular}{lllll}
\hline Item & Response & SN60WF group (\%) & ZCB00 group (\%) & P-value \\
\hline Number of days per week & $\geq 5$ & 57.5 & 65.6 & 34.4 \\
& $<5$ & 42.5 & $2.844 \pm 0.920$ & $0.482^{*}$ \\
Number of places per day & & $2.750 \pm 1.214$ & $1.525 \pm 1.580$ & 6.5 \\
Number of places per week & & $2.526 \pm 4.183$ & 34.4 & $0.162^{\#}$ \\
Number of miles per day & $\geq 5$ & 62.5 & 3.1 & $0.79 I^{*}$ \\
Number of people that regularly travel with you & $\geq 5$ & 30.0 & 96.9 & $0.42 I^{*}$ \\
& $\geq 4$ & 7.5 & 43.8 & 21.9 \\
When traveling with others, do you usually drive? & Yes & 92.5 & 28.1 \\
\end{tabular}

Notes: $* \chi^{2}$ test; ${ }^{*}$ analysis of variance.

Abbreviation: DHQ, Driving Habits Questionnaire.

cessation, including being physically unable, cancer, stroke, dementia, and other.

Respondents said that on a typical day, they drove to between two and three places (SN60WF group 2.75 \pm 1.21 , ZCB00 group 2.84 $\pm 0.92 ; P=0.710$ ), and during a typical week they might drive to one to three places (SN60WF group $2.53 \pm 4.18$, ZCB00 group $1.525 \pm 1.58 ; P=0.162$ ). The majority of respondents in both groups drove $\geq 5$ miles $(8.05 \mathrm{~km})$ in a typical day and drove at least 5 days per week (Table 3 ).

Tables 4 and 5 show the DHQ responses of the two groups to questions about driving in more challenging conditions and about how far from home they had driven in the past year. Compared to the ZCB00-implanted subjects, the SN60WF-implanted subjects were less likely to have traveled beyond their immediate neighborhood, less likely to drive at night, and more likely to have moderate-to-severe difficulty driving at night. The four SN60WF subjects who reported moderate-to-severe difficulty driving at night identified the following reasons: "Glare from oncoming headlights" (three) and "Might miss something" (three). The 1 ZCB00 subject who reported moderate-to-severe difficulty did not give a reason. The differences did not reach statistical significance.

The SN60WF-implanted subjects also reported being involved as a driver in more traffic accidents than the ZCB00-implanted subjects (Table 6). The accidents were self-reported, and were not verified against driving records or categorized by type of accident.

Table 4 Driving Habits Questionnaire: Driving difficulty

\begin{tabular}{|c|c|c|c|c|}
\hline $\begin{array}{l}\text { During the past } 3 \text { months, have you experienced } \\
\text { difficulty... }\end{array}$ & Response & SN60WF group (\%) & ZCB00 group (\%) & $P$-value* \\
\hline \multirow[t]{2}{*}{ Driving when it is raining? } & No difficulty & 90.0 & 90.6 & 0.929 \\
\hline & Difficulty & 10.0 & 9.4 & \\
\hline \multirow[t]{2}{*}{ Driving alone? } & No difficulty & 100 & 100 & NA \\
\hline & Difficulty & 0 & 0 & \\
\hline \multirow[t]{2}{*}{ Parallel parking? } & No difficulty & 65.0 & 78.1 & 0.223 \\
\hline & Difficulty & 35.0 & 21.9 & \\
\hline \multirow[t]{2}{*}{ Making left-hand turns across oncoming traffic? } & No difficulty & 92.5 & 90.6 & 0.775 \\
\hline & Difficulty & 7.5 & 9.4 & \\
\hline \multirow[t]{2}{*}{ Driving on highways? } & No difficulty & 75.0 & 81.3 & 0.526 \\
\hline & Difficulty & 25.0 & 18.8 & \\
\hline \multirow[t]{2}{*}{ Driving on high-traffic roads? } & No difficulty & 87.5 & 93.8 & 0.374 \\
\hline & Difficulty & 12.5 & 6.3 & \\
\hline \multirow[t]{2}{*}{ Driving at night? } & No difficulty & 82.5 & 93.8 & 0.151 \\
\hline & Difficulty & 17.5 & 6.3 & \\
\hline \multirow[t]{2}{*}{ Driving at night with moderate-to-severe difficulty? } & No difficulty & 10.0 & 3.1 & 0.197 \\
\hline & Difficulty & 72.5 & 90.6 & \\
\hline \multirow[t]{2}{*}{ Driving in rush-hour traffic? } & No difficulty & 82.5 & 87.5 & 0.558 \\
\hline & Difficulty & 17.5 & 12.5 & \\
\hline
\end{tabular}

Note: $* \chi^{2}$ test.

Abbreviation: NA, not applicable. 
Table 5 Driving Habits Questionnaire: Driving space

\begin{tabular}{lllll}
\hline In the past year, have you driven... & Response & SN60WF group (\%) & ZCB00 group (\%) & P-value* \\
\hline In your immediate neighborhood? & Yes & 100 & 100 & NA \\
& No & 0 & 0 & 100 \\
Beyond the neighborhood? & Yes & 92.5 & 0 & 0.114 \\
& No & 7.5 & 96.9 & 0.421 \\
To neighboring towns? & Yes & 92.5 & 3.1 & 34.4 \\
Outside the province? & No & 7.5 & 65.6 & 0.692 \\
Outside central Canada? & Yes & 30.0 & 21.9 & 0.584 \\
& No & 70.0 & 78.1 & \\
\hline
\end{tabular}

Note: $* \chi^{2}$ test.

Abbreviation: NA, not applicable.

This study suggests that IOL type implanted at the time of cataract surgery may affect patients' driving habits 2-3 years after cataract surgery. A larger study, powered to demonstrate statistical significance, is needed to confirm these findings.

\section{Discussion}

Maintaining the ability to drive - and drive safely - is important for the well-being and independence of older adults. Cataract surgery typically improves visual performance for driving.

One of the reasons that cataract surgery is beneficial is that it reduces disability glare, which can have a major impact on driving safety and driving habits. Ocular sources of the retinal straylight that causes disability glare include 1) corneal opacities, 2) lenticular opacities, 3) asteroid hyalosis or vitreous opacities, 4) IOL designs and defects, and 5) posterior capsular opacification (PCO).

For the purposes of this study, the first three sources of disability glare were effectively ruled out, because this study was conducted among pseudophakic patients with healthy eyes. The increase in visual difficulties several years after cataract surgery may be due to increased disability glare arising from either PCO or IOL designs or defects affecting quality of vision through the IOL.
The subjects were not examined to determine the actual presence of or reasons for disability glare. However, it is highly unlikely that differences in PCO accounted for the changes in driving patterns seen in this study. The reported rates of $\mathrm{PCO}$ and neodymium-doped yttrium aluminum garnet (Nd:YAG) laser treatment after implantation with IOLs made from the same materials discussed here have previously been found to be comparable at 3 years postoperatively (ZCB00 and SA60AT) ${ }^{16}$ and at 5-7 years postoperatively (SA60AT and Sensar AR40e). ${ }^{17}$ In another study, the AcrySof material (SA60AT) was associated with a lower incidence of Nd:YAG laser treatment than the Sensar material (AR40E) 3 years after surgery, ${ }^{18}$ so if there is any difference in PCO rates between the two groups, it should favor the AcrySof material and the SN60WF group. The possibility that lens design and defects may be the explanation for the night-driving difficulties and changes in driving habits reported by the SN60WF subjects in this study needs to be considered.

Hydrophobic acrylic IOLs are the most commonly used lenses in contemporary cataract surgery. It has long been known that some hydrophobic acrylic IOL materials are predisposed to "glistenings" or microvacuoles that develop over time. ${ }^{19-21}$ By $2-3$ years after implantation, glistenings are present in more than $94 \%$ of AcrySof IOLs, ${ }^{21,22}$ with the majority $(60 \%-87 \%)$ rated moderate- to severe-grade glistenings. ${ }^{21}$

Table 6 Driving Habits Questionnaire: Self-reported crashes and citations

\begin{tabular}{|c|c|c|c|c|}
\hline In the past year, have you... & Response & SN60WF group (\%) & ZCB00 group (\%) & P-value* \\
\hline \multirow[t]{2}{*}{ Been involved in an accident when you were the driver? } & Yes & 10.0 & 0 & 0.066 \\
\hline & No & 90.0 & 100 & \\
\hline Been pulled over by police, regardless of whether & Yes & 7.5 & 6.3 & 0.836 \\
\hline you received a ticket? & No & 92.5 & 93.8 & \\
\hline \multirow[t]{2}{*}{ Received a traffic ticket (other than a parking ticket)? } & Yes & 7.5 & 3.1 & 0.421 \\
\hline & No & 92.5 & 96.9 & \\
\hline
\end{tabular}

Note: ${ }^{*} \chi^{2}$ test. 
Behndig and Mönestam noted that IOL glistenings increase exponentially over time, and are not stable even as long as 10 years postoperatively. ${ }^{23}$ Light-scatter comparisons between AcrySof and Sensar materials found that the light scatter continued to increase with AcrySof 15 years postoperatively without any leveling off, while light scatter with Sensar over the same time period was low and had leveled off by 1 year postoperatively. ${ }^{24}$ The ZCB00 is made of the same material as the Sensar, and would be expected to display a similar degree of microvacuole formation.

Microvacuoles have been associated with retinal straylight and glare in in vitro studies. Most recently, van der Mooren et al demonstrated that two types of IOLs (AcrySof and Hoya iSymm) possessed significant glistenings that contributed to straylight levels higher than that of a healthy 20-year-old crystalline lens. ${ }^{25}$

It is very likely that by the time period of this study (2-3 years postoperatively), microvacuoles were present in the SN60WF lenses, and that all or most of the SN60WFimplanted subjects in this study likely had some degree of retinal light scatter from these microvacuoles. Whether microvacuoles were contributory to changing driving habits needs to be investigated.

Long-term limitation of driving habits following cataract surgery has previously been reported: it was found that subjective driving ability 5 years after cataract surgery in eyes primarily (96\%) implanted with MA60BM lenses ${ }^{13}$ was decreased compared to the immediate postoperative period. One of the authors of this paper has previously noted that microvacuoles in the AcrySof lenses increase over time, ${ }^{23}$ so the possible contributory role of glistenings to retinal straylight and disability glare needs to be considered.

In laboratory testing, lens defects certainly diminish optical performance. Clinically, it is not conclusively known to what degree visual performance is affected by the presence of microvacuoles and glistenings. Snellen visual acuity seems to be rarely affected by IOL glistenings, leading some to conclude they have no impact on visual performance. However, a number of clinical studies have shown a correlation between glistenings and reduced contrast sensitivity, particularly at higher spatial frequencies. ${ }^{26,27}$

It is possible that the blue light-filtering yellow chromophore in the SN60WF AcrySof lenses reduces the effects of disability glare compared to clear lenses. ${ }^{28,29}$ In studies demonstrating these benefits, however, the clear-lens control groups without the blue-light filter (SA60AT) had been implanted longer than the comparison groups with the blue-light filter, which implies that they had more time to develop microvacuoles (this confounding influence was not accounted for in the discussion of the paper). However, if we accept the conclusions of the authors, then the SN60WF group should have had less disability glare than the ZCB00 group because of the chromophore; however, the SN60WF group in our retrospective review had symptoms suggestive of greater disability glare.

The major limitations of the findings in this paper are that it is a retrospective study conducted using a questionnaire and that statistical significance was not reached. The questionnaire is a validated questionnaire that has been reviewed in previous publications. . $^{3,9,11,15}$

Although statistical significance was not attained in this study, there is a clear trend across multiple measures, including the rate of self-reported accidents that favors one IOL type over another, suggesting that IOL material and design may be contributory. With a low-powered pilot study, it would be surprising to find near-significance on so many variables in the same direction if the findings were due to chance alone. A higher-powered study is necessary.

The significance of this study is that it raises concerns regarding whether the initial short-term benefits of improved visual performance and increased driving habits derived from cataract surgery are sustained in the long term following cataract surgery. Additionally, there may be an impact due to lens material on driving habits. Although the current pilot study did not find statistically supported significance for these concerns, it was able to provide information regarding follow-up investigations. Based on the current pilot-study findings, 120-125 patients in each lens group (240-250 total) would be needed to confirm statistical significance of the trends identified in this pilot at a significance level of 0.05 and $95 \%$ confidence interval. Enrollment for this study, which will also examine subjects to determine the causes of disability glare, is under way.

\section{Acknowledgments}

Financial support in the form of a grant was provided by Abbott Medical Optics. The sponsor played no role in study design, data collection, or data analysis. Assistance in the preparation of this manuscript was provided by Wordsmith Consulting, with funding from Abbott Medical Optics. The author also wishes to thank Taylor Lukasik, MD candidate, for assistance with data collection.

\section{Disclosure}

The author is a consultant for Abbott Medical Optics (AMO), and has received research or travel funding from AMO, Bausch and Lomb, Croma, and the Stormoff Group. 


\section{References}

1. Rubin GS, Adamson IA, Stark WJ. Comparison of acuity, contrast sensitivity, and disability glare before and after cataract surgery. Arch Ophthalmol. 1993;111:56-61.

2. Owsley C, Stalvey BT, Wells J, Sloane ME, McGwin G Jr. Visual risk factors for crash involvement in older drivers with cataract. Arch Ophthalmol. 2001;119:881-887.

3. Owsley C, Stalvey V, Wells J, Sloane ME. Older drivers and cataract: driving habits and crash risk. J Gerontol A Biol Sci Med Sci. 1999;54: M203-M211.

4. Van Den Berg TJ, Van Rijn LJ, Michael R, et al. Straylight effects with aging and lens extraction. Am J Ophthalmol. 2007;144:358-363.

5. Van Den Berg TJ, Franssen L, Coppens JE. Ocular media clarity and straylight. In: Dartt DA, editor. Encyclopedia of the Eye. Vol 3. Oxford, UK: Oxford University Press; 2010:173-183.

6. Ball K, Owsley C, Stalvey B, Roenker D, Sloane M, Graves M. Driving avoidance and functional impairment in older drivers. Accid Anal Prev. 1998;30:313-322.

7. Schlag G. Elderly drivers in Germany-fitness and driving behavior. Accid Anal Prev. 1993;25:47-56.

8. Marottoli RA, Ostfeld AM, Merrill SS, Perlman GD, Foley DJ, Cooney LM Jr. Driving cessation and changes in mileage driven among elderly individuals. J Gerontol. 1993;48:S255-S260.

9. Fraser ML, Meuleners LB, Ng JQ, Morlet N. Driver self-regulation and depressive symptoms in cataract patients awaiting surgery: a crosssectional study. BMC Ophthalmol. 2013;13:45.

10. Michael R, Barraquer RI, Rodríguez J, et al. Intraocular straylight screening in medical testing centres for driver license holders in Spain. J Optom. 2010;3:107-114.

11. Sandlin D, McGwin G, Owsley C. Association between vision impairment and driving exposure in older adults aged 70 years and over: a population-based examination. Acta Ophthalmol. 2014;92:e207-e212.

12. Owsley C, McGwin G Jr, Sloane M, Wells J, Stalvey BT, Gauthreaux S. Impact of cataract surgery on motor vehicle crash involvement by older adults. JAMA. 2002;288:841-849.

13. Mönestam E, Lundquist B, Wachtmeister L. Visual function and car driving: longitudinal results 5 years after cataract surgery in a population. Br J Ophthalmol. 2005;89:459-463.

14. Fraser ML, Meuleners LB, Lee AH, Ng JQ, Morlet N. Which visual measures affect change in driving difficulty after first eye cataract surgery? Accid Anal Prev. 2013;58:10-14

15. Owsley C, McGwin G Jr, Elgin J, Wood JM. Visually impaired drivers who use bioptic telescopes: self-assessed driving skills and agreement with on-road driving evaluation. Invest Ophthalmol Vis Sci. 2014;55: $330-336$
16. Leydolt C, Kriechbaum K, Schriefl S, Pachala M, Menapace R. Posterior capsule opacification and neodymium:YAG rates with 2 single-piece hydrophobic acrylic intraocular lenses: three-year results. J Cataract Refract Surg. 2013;39:1886-1892.

17. Chang A, Behndig A, Rønbeck M, Kugelberg M. Comparison of posterior capsule opacification and glistenings with 2 hydrophobic acrylic intraocular lenses: 5- to 7-year follow-up. J Cataract Refract Surg. 2013;39:694-698.

18. Boureau C, Lafuma A, Jeanbat V, Berdeaux G, Smith AF. Incidence of Nd:YAG laser capsulotomies after cataract surgery: comparison of 3 square-edged lenses of different composition. Can JOphthalmol. 2009;44: $165-170$.

19. Colin J, Orignac I. Glistenings on intraocular lenses in healthy eyes: effects and associations. J Refract Surg. 2011;27:869-875.

20. Colin J, Orignac I, Touboul D. Glistenings in a large series of hydrophobic acrylic intraocular lenses. J Cataract Refract Surg. 2009;35: 2121-2126.

21. Leydolt C, Schriefl S, Stifter E, Haszcz A, Menapace R. Posterior capsule opacification with the iMics1 NY-60 and AcrySof SN60WF 1-piece hydrophobic acrylic intraocular lenses: 3-year results of a randomized trial. Am J Ophthalmol. 2013;156:375-381.

22. Colin J, Praud D, Touboul D, Schweitzer C. Incidence of glistenings with the latest generation of yellow-tinted hydrophobic acrylic intraocular lenses. J Cataract Refract Surg. 2012;38:1140-1146.

23. Behndig A, Mönestam E. Quantification of glistenings in intraocular lenses using Scheimpflug photography. J Cataract Refract Surg. 2009;35: 14-17.

24. Miyata K, Honbo M, Otani S, Nejima R, Minami K. Effect on visual acuity of increased surface light scattering in intraocular lenses. $J$ Cataract Refract Surg. 2012;38:221-226.

25. van der Mooren M, Franssen L, Piers P. Effects of glistenings in intraocular lenses. Biomed Opt Express. 2013;4:1294-1304.

26. Dhaliwal DK, Mamalis N, Olson RJ, et al. Visual significance of glistenings seen in the AcrySof intraocular lens. J Cataract Refract Surg. 1996; 22:452-457.

27. Waite A, Faulkner N, Olson RJ. Glistenings in the single-piece, hydrophobic, acrylic intraocular lenses. Am J Ophthalmol. 2007;144: 143-144.

28. Hammond BR, Bernstein B, Dong J. The effect of the AcrySof natural lens on glare disability and photostress. Am J Ophthalmol. 2009;148: 272-276.

29. Gray R, Perkins SA, Suryakumar R, Neuman B, Maxwell WA. Reduced effect of glare disability on driving performance in patients with blue light-filtering intraocular lenses. J Cataract Refract Surg. 2011;37: $38-44$.
Clinical Ophthalmology

\section{Publish your work in this journal}

Clinical Ophthalmology is an international, peer-reviewed journal covering all subspecialties within ophthalmology. Key topics include: Optometry; Visual science; Pharmacology and drug therapy in eye diseases; Basic Sciences; Primary and Secondary eye care; Patient Safety and Quality of Care Improvements. This journal is indexed on Submit your manuscript here: http://www.dovepress.com/clinical-ophthalmology-journal

\section{Dovepress}

PubMed Central and CAS, and is the official journal of The Society of Clinical Ophthalmology (SCO). The manuscript management system is completely online and includes a very quick and fair peer-review system, which is all easy to use. Visit http://www.dovepress.com/ testimonials.php to read real quotes from published authors. 